\title{
Detection of Ampc and Extended-Spectrum Beta-Lactamases in Clinical Isolates of Pseudomonas Aeruginosa from Patients with Cystic Fibrosis
}

\author{
Roya Rafiee (MSc) \\ Department of Microbiology, Faculty \\ of Biological Sciences, Shahid \\ Beheshti University, Tehran, Iran \\ Fereshte Eftekhar (PhD) \\ Department of Microbiology, Faculty \\ of Biological Sciences, Shahid \\ Beheshti University, Tehran, Iran \\ Seyed Ahmad Tabatabaei (PhD) \\ Department of Pediatrics, Shahid \\ Beheshti University of Medical \\ Sciences, Tehran, Iran \\ Dariush Minaee-Tehrani (PhD) \\ Department of Microbiology, Faculty \\ of Biological Sciences, Shahid \\ Beheshti University, Tehran, Iran \\ Corresponding Author: Fereshte \\ Eftekhar \\ Email: F-Eftekhar@sbu.ac.ir \\ Tel: 29903208
}

Adderess: Faculty of Biological Sciences, Shahid Beheshti University, Tehran, Iran

Received : 24 May 2015

Revised: 20 Sep 2015

Accepted: 20 Sep 2015

\section{ABSTRACT}

Background and Objectives: Pseudomonas aeruginosa is the most frequent opportunistic pathogen isolated from the sputum of patients with cystic fibrosis (CF). Resistance to $\beta$-lactam antibiotics may arise from over expression of the naturally occurring AmpC cephalosporinases or acquired extended-spectrum $\beta$-lactamases (ESBL). The aim of this study was to determine the antibiotic resistance profiles as well as the prevalence of ESBL and AmpC production in clinical isolates of $P$. aeruginosa from CF patients in Tehran.

Methods: Antibiotic resistance of 50 non-duplicate $P$. aeruginosa isolates was determined by the disc diffusion method. AmpC $\beta$-lactamase production was detected by the antagonism disc test and ESBL production was detected by the phenotypic confirmatory test. The presence of ESBL and AmpC genes was assessed by PCR, followed by sequencing the PCR products.

Results: The antibiotic resistance rates were as follows: $22 \%$ to ceftriaxone, $20 \%$ to cefotaxime, $10 \%$ to imipenem, $8 \%$ to carbenicillin and $6 \%$ to ticarcillin, $4 \%$ each to cefepime, tobramycin, amikacin and aztreonam and $2 \%$ to each piperacilin, meropenem and ceftazidime. AmpC production was observed in 47 isolates (94\%) and ESBL production was observed in one isolate (2\%). PCR results showed that all isolates carried the bla $a_{\mathrm{AmpC}} \beta$ lactamase gene. 0 ne multidrug-resistant isolate carried both bla $a_{\text {TEN }}$ and $b a_{\text {PER- }}$ genes.

Conclusion: The results showed that despite the low rate of antibiotic resistance in $P$. aeruginosa CF isolates, the presence of multiple $\beta$-lactamases even in one isolate is alarming and can complicate the already difficult treatment of chronic infections in the lungs of CF patients.

KEYWORDS: Pseudomonsa aeruginosa; Cystic Fibrosis; ESBL, AmpC, BetaLactamases.

This paper should be cited as: Rafiee R, Eftekhar F, Tabatabaei S A, Minaee-Tehrani D, [Detection of Ampc and Extended-Spectrum Beta-Lactamases in Clinical Isolates of Pseudomonas Aeruginosa from Patients with Cystic Fibrosis]. ml.jqoums. 2016; 10(3): 28-32 


\section{INTRODUCTION}

Chronic Pseudomonas aeruginosa lung infection is the main cause of morbidity and mortality in cystic fibrosis (CF) patients. About $80 \%$ of adults with CF suffer from the chronic $P$. aeruginosa infection $(1,2)$. In the lung of $\mathrm{CF}$ patients, $P$. aeruginosa exhibits several genotypic and phenotypic changes such as antibiotic resistance and mucoid conversion (3). P. aeruginosa uses a wide variety of different resistance mechanisms and is essentially resistant to all classes of commonly used antibiotics (4). Several mechanisms are responsible for resistance to $\beta$-lactam antibiotics in $P$. aeruginosa including over expression of chromosomally mediated AmpC cephalosporinases, acquisition of transferable $\beta$-lactamase genes such as extended-spectrum $\beta$-lactamases (ESBLs) and metallo- $\beta$-lactamases (MBLs), presence of efflux systems, and reduced membrane permeability $(5,6)$. In $P$. aeruginosa, the decreased susceptibility to the extendedspectrum cephalosporins such as ceftazidime mostly results from over expression of the naturally occurring AmpC $\beta$-lactamases (6). ESBLs are capable of hydrolyzing penicillins, cephalosporins and aztreonam (except for cephamycins or carbapenems). These enzymes are inhibited by $\beta$-lactamase inhibitors such as clavulanic acid (7). Up to 32 different ESBLs have been detected in $P$. aeruginosa belonging to class A (TEM, SHV, CTX-M, PER, VEB, GES, BEL), and class D (OXA type) $\beta$ lactamases (8). We studied the antibiotic resistance profiles in clinical isolates of $P$. aeruginosa from $\mathrm{CF}$ patients, by phenotypic detection of AmpC and ESBL production and their comparison in the presence of $\mathrm{AmpC}$, TEM, SHV, CTX-M, PER and VEB $\beta$ lactamase genes among these isolates.

\section{MATERIAL AND METHODS}

Fifty non-duplicate clinical isolates of $P$. aeruginosa were collected from CF patients at Mofid Children's Hospital in Tehran between July 2012 and February 2013. Twenty-nine $(58 \%)$ isolates were obtained from males and $21(42 \%)$ were obtained from female patients (age range, 6 months to 26 years). The mean age $( \pm$ SD) was $92.52( \pm 70.99)$ months with a median of 72 months. The isolates were identified by Gram staining and conventional microbiological tests including oxidase production, blue-green pigmentation on Mueller Hinton agar [MHA, (Liofilchem,
Italy)], acid and gas production on triple sugar iron agar slants (BBL, USA), and growth at $42^{\circ} \mathrm{C}$ (9). The isolates were maintained in brain heart infusion broth (Oxoid, UK) containing $10 \%$ dimethyl sulfoxide at $-20{ }^{\circ} \mathrm{C}$ until use. $P$. aeruginosa PAO1 containing $b l a_{A m p C}$ (kindly provided by Dr Abdi, Alzahra University, Iran), DNA from $K$. pneumoniae 7881 harboring bla $_{T E M}, b l a_{S H V}$ and $b l a_{C T X-M}, P$. aeruginosa KOAS carrying bla PER-1 and $P$. aeruginosa 10.2 harboring bla VEB-I $_{\text {(obtained }}$ from Pasteur Institute, Tehran, Iran) were used as controls for PCR experiment. P. aeroginosa ATCC 27853 was used as control for susceptibility tests. Antibiotic susceptibility testing of the isolates was carried out by the disc diffusion method according to the Clinical and Laboratory Standard Institute (CLSI) guidelines (10). The antibiotic discs (MAST Group LTD, Merseyside, UK) used in this study included: ceftazidime $(30 \mu \mathrm{g})$, cefotaxime $(30 \mu \mathrm{g})$, ceftriaxone $(30 \mu \mathrm{g})$, cefepime $(30 \mu \mathrm{g})$, cefoxitin $(30 \mu \mathrm{g})$, imipenem $(10 \mu \mathrm{g})$, meropenem $(10 \mu \mathrm{g})$, carbenicillin $(100 \mu \mathrm{g})$, ticarcillin $(75 \mu \mathrm{g})$, piperacillin $(100$ $\mu \mathrm{g})$, amikacin $(30 \mu \mathrm{g})$, tobramycin $(10 \mu \mathrm{g})$ and aztreonam $(30 \mu \mathrm{g})$. Minimum inhibitory concentrations (MICs) for imipenem and ceftazidime were determined by the microdilution assay as recommended by the CLSI (10). Initial screening for AmpC $\beta$ lactamase production was performed by the disc antagonism test on the isolates showing a zone diameter of $<18 \mathrm{~mm}$ to cefoxitin disc (11). Briefly, a lawn culture of each test isolate (0.5 Mc Farland) was prepared on a MHA plate, and then ceftazidime $(30 \mu \mathrm{g})$ and cefoxitin $(30 \mu \mathrm{g})$ discs were placed $20 \mathrm{~mm}$ (centre to centre) apart from each other followed by incubation at $37{ }^{\circ} \mathrm{C}$ for $18-20$ hours. Inducible AmpC $\beta$-lactamase production was detected when blunting of ceftazidime inhibition zone occurred adjacent to the cefoxitin disc. ESBL production was detected by the conventional double disc synergy test using ceftazidime $(30 \mu \mathrm{g})$ and cefotaxime discs $(30 \mu \mathrm{g})$ with or without clavulanic acid $(10 \mu \mathrm{g})$ as recommended by the CLSI (10). An increase of $\geq 5 \mathrm{~mm}$ in the inhibition zone of either cephalosporin in combination with clavulanic acid compared to the cephalosporin alone was interpreted as ESBL production. DNA extraction was performed by boiling method. Briefly, a 
loopful of an overnight grown culture of each isolate was suspended in $500 \mu \mathrm{l}$ of sterile double distilled water, boiled at $100{ }^{\circ} \mathrm{C}$ for 10 min and then centrifuged at $12000 \mathrm{~g}$ for 10 min. The supernatant was used as DNA template for PCR amplification tests. PCR amplifications were performed using specific primers for Ambler class A (bla $a_{T E M}, b l a_{S H V}$, bla $\left._{\text {CTX-M }}, \quad b l a_{V E B-1}, \quad b l a_{P E R-1}\right)$ and class C $\left(b l a_{\text {AmpC }}\right) \beta$-lactamase genes (Table 1). PCR experiments were carried out in $25 \mu \mathrm{l}$ volume reaction mixtures containing $10 \mathrm{pM}$ of each primer, $200 \mu \mathrm{M}$ dNTP, $1.4 \mathrm{mM} \mathrm{MgCl} 2,1 \mu \mathrm{l}$ of DNA template and $1 \mathrm{U}$ of Taq polymerase in the reaction buffer provided by the manufacturer (CinnaGen, Tehran, Iran). PCR process was carried out in a thermocycler (Techne, UK) using the following program: 5 min denaturation at $95{ }^{\circ} \mathrm{C}$, followed by 30 cycles at $95{ }^{\circ} \mathrm{C}$ for $1 \mathrm{~min}, 1 \mathrm{~min}$ at the annealing temperature $\left(43-63^{\circ} \mathrm{C}\right.$ for ESBLs and $62^{\circ} \mathrm{C}$ for AmpC), 1 min at $72^{\circ} \mathrm{C}$ and final extension for $10 \mathrm{~min}$ at $72{ }^{\circ} \mathrm{C}$. Correlation of $\beta$-lactamase phenotypes with their related genes was assessed using the chi-square test. The relationship between antibiotic resistance and $\beta$-lactamase gene carriage was analyzed by the nonparametric Mann-Whitney $U$ test. All statistical analyses were carried out using SPSS software version 20. $P$-value of $\leq 0.05$ was considered statistically significant.

\section{RESULTS}

Among the $50 \mathrm{CF}$ isolates, 48 (96\%) were resistant to cefoxitin, one was susceptible, and one showed intermediate resistance. Resistance rates to other antibiotics were as follows (Figure 1): ceftriaxone (22\%), cefotaxime (20\%), imipenem (10\%), carbenicillin (8\%), ticarcillin (6\%), cefepime, amikacin, tobramycin and aztreonam (4\%) and piperacilin, ceftazidime and meropenem (2\%). Overall, the highest resistance rate was to ertapenem and the lowest was to piperacilin, ceftazidime and meropenem. One isolate $(2 \%)$ was multidrug-resistant with MIC $\geq 16 \mu \mathrm{g} / \mathrm{ml}$ for imipenem and $\geq 128 \mu \mathrm{g} / \mathrm{ml}$ for ceftazidime.

Table1- Primers used for PCR detection of ESBLs and AmpC genes

\begin{tabular}{|c|c|c|c|c|}
\hline$\beta$-lactamase & Primer & Sequence (5' to 3 ') & $\begin{array}{c}\begin{array}{c}\text { Product size } \\
\text { (bp) }\end{array} \\
\end{array}$ & Reference \\
\hline \multirow[t]{10}{*}{ Class A } & TEM-F & GAGTATTCAACATTTCCGTGTC & 851 & 12 \\
\hline & TEM-R & TAATCAGTGAGGCACCTATCTC & & \\
\hline & SHV-F & AAGATCCACTATCGCCAGCAG & 231 & 12 \\
\hline & SHV-R & ATTCAGTTCCGTTTCCCAGCGG & & \\
\hline & CTX-M-F & CGCTTTGCGATGTGCAG & 550 & 13 \\
\hline & CTX-M-R & ACCGCGATATCGTTGGT & & \\
\hline & PER-1-F & ATGAATGTCATTATAAAAGC & 920 & 12 \\
\hline & PER-1-R & AATTTGGGCTTAGGGCAGAA & & \\
\hline & VEB-1-F & CGACTTCCATTTCCCGATGC & 643 & 12 \\
\hline & VEB-1-R & GGACTCTGCAACAAATACGC & & \\
\hline \multirow[t]{2}{*}{ Class C } & AmpC-F & ATGCAGCCAACGACAAAGG & 1243 & 14 \\
\hline & AmpC-R & CGCCCTCGCGAGCGCGCTTC & & \\
\hline
\end{tabular}

Figure 1-Antibiotic resistance profiles of the 50 P. aeruginosa CF isolates. CAZ, ceftazidime; CTX, cefotaxime; CRO, ceftriaxone; CPM, cefepime; IPM, imipenem; MEM, meropenem; PY, carbenicillin; TC, ticarcillin; PRL, piperacilin: AK. amikacin: TN. tobramvcin: ATM. aztreonam.

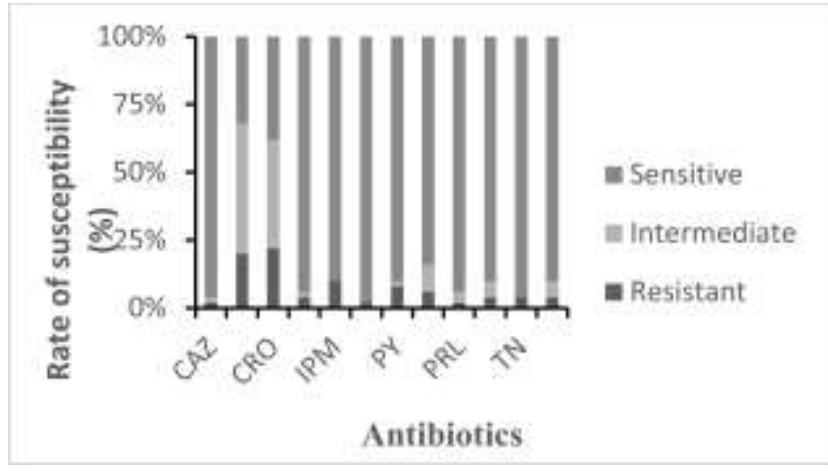


Figure 2- PCR amplification of $\beta$-lactamase genes in the $P$. aeruginosa $C F$ isolates. (A): bla $a_{\mathrm{Amp}}$ amplification product; M, $1 \mathrm{Kbp}$ DNA ladder, C; positive control. (B): bla $a_{\mathrm{PER}}$ and bla $\boldsymbol{T}_{\mathrm{TEM}}$ amplification products; M: 100 bp: C. positive control

(A)

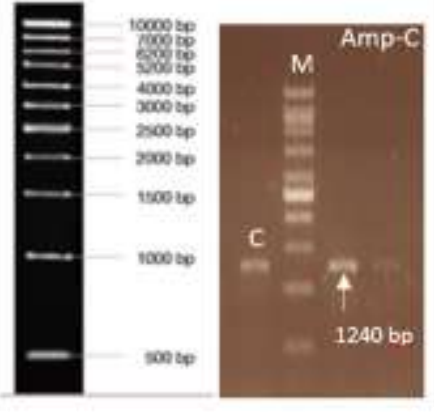

(B)

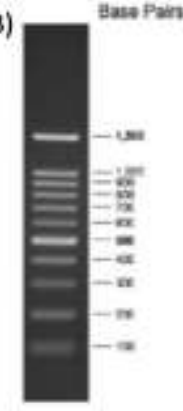

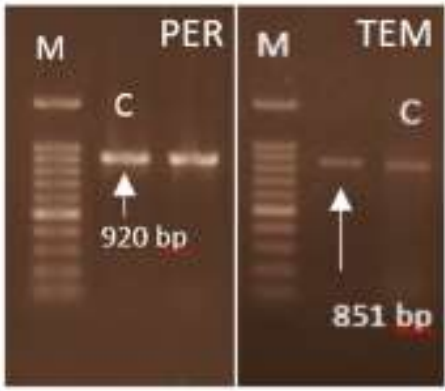

AmpC production was observed in 47 isolates (94\%) and ESBL phenotype was detected in one isolate $(2 \%)$. PCR amplification results showed that all isolates carried the $b l a_{\mathrm{AmpC}} \beta$ lactamase gene and the multidrug-resistant isolate carried $b l a_{\mathrm{AmpC}}, b l a_{\mathrm{TEM}}$ and $b l a_{\mathrm{PER}-1}$ genes (Figure 2). bla $a_{\mathrm{SHV}}, b_{\mathrm{CTX}-\mathrm{M}}$ and bla $_{\mathrm{VEB}}$ genes were not detected in any of the isolates. Sequence analysis of the PCR products showed the presence of a new allele for the bla ${ }_{\text {TEM }}$ gene (www.lahey.org/studies/temtable.asp) (15). Overall, there was a good correlation between $\beta$-lactamase phenotype and its related gene carriage among the tested isolates $(p<0.05)$.

\section{DISCUSSION}

$\beta$-lactam antibiotics are often inefficient in the treatment of $P$. aeruginosa lung infections. The main reasons for treatment failure are thought to be ESBL production, hyperproduction of chromosomally encoded AmpC $\beta$-lactamases and biofilm formation (1). The current CLSI guidelines have not provided a method for detection of AmpC $\beta$-lactamases. It has been suggested that cefoxitin-resistant isolates (showing a zone diameter of $<18 \mathrm{~mm}$ to cefoxitin disc) are potential AmpC $\beta$ lactamase producers and the disc antagonism test should be used for screening AmpC $\beta$ lactamase production in these isolates $(11,16)$. In this study, all $50 \mathrm{CF}$ isolates carried the bla $a_{\mathrm{AmpC}}$ gene, while 47 isolates (94\%) were AmpC producers. These results show a good correlation between AmpC gene carriage and AmpC phenotype among the isolates. Of the three $b l a_{\mathrm{AmpC}}$ positive and AmpC negative isolates, one was susceptible to all tested antibiotics, two were resistant to cefoxitin, and one also showed intermediate resistance to cefotaxime. However, the susceptibility of these isolates to other $3^{\text {rd }}$ generation cephalosporins was not investigated in the present study. The presence of genes does not necessarily mean that they are expressed, which could be influenced by the environment as well as other regulatory mechanisms. Limited number of studies on AmpC production by $P$. aeruginosa $\mathrm{CF}$ isolates are available. In a study in Africa, AmpC production was not detected in any of the $15 P$. aeruginosa isolates from CF patients (17).

The rate of ESBL production in $P$. aeruginosa $\mathrm{CF}$ isolates varies worldwide. In a study in Iran, Vali et al. showed that $9.6 \%$ of $52 P$. aeruginosa $\mathrm{CF}$ isolates carried bla ${ }_{\mathrm{CTX}-\mathrm{M}}(18)$. Another study in Iran detected the $b l a_{\text {PER-1 }}$ gene in $10 \%$ of $P$. aeruginosa CF isolates (19). Mhlongo et al. reported the ESBL phenotype in all of their tested isolates (17). Other studies have reported the presence of $b l a_{\mathrm{CTX}-\mathrm{M}}$ gene and coproduction of PER-1 and VIM-2 in one $P$. aeruginosa $\mathrm{CF}$ isolate $(20,21)$. We found ESBL production in one multidrug-resistant isolate, which also carried $b l a_{\mathrm{AmpC}}, b l a_{\mathrm{TEM}}$ and bla $_{\text {PER-1 }}$ genes. Overall, the spread of different ESBL genes in $P$. aeruginosa $\mathrm{CF}$ isolates is increasing. The discrepancy between $\beta$ lactamase phenotype and gene carriage could be due to environmental conditions such as the presence of antibiotics that may allow the expression of $\beta$-lactamase genes in vivo but not in vitro.

\section{CONCLUSION}

The results showed that despite the low rate of antibiotic resistance in $P$. aeruginosa CF Isolates, the presence of $\beta$-lactamase genes could lead to their 
expression under selective environmental pressures such as extensive use of antibiotics, resulting in treatment failure in these infections. In addition, resistance genes from even one multidrug-resistant isolate can spread among the susceptible strains and cause increased morbidity and mortality among the CF patients.

\section{REFERENCES}

1. Ciofu O, Tolker-Nielsen T, Jensen PO, Wang H, HØiby N. Antimicrobial resistance, respiratory tract infections and role of biofilms in lung infections in cystic fibrosis patients. Adv Drug Deliv Rev. 2015; 85: 7-23. doi: 10.1016/j.addr.2014.11.017.

2. Keating DJ, Acquazzino D, Goering RV, Sammut P, Khalaf N, Hanson ND. Molecular detection of an atypical, highly resistant, clonal Pseudomonas aeruginosa isolate in cystic fibrosis patients. J Cyst Fibros. 2013; 12(2): 141-6. doi: 10.1016/j.jcf.2012.07.007.

3. Wolter DJ, Acquazzino D, Goering R V, Sammut P, Khalaf N, Hanson ND. Emergence of carbapenem resistance in Pseudomonas aeruginosa isolates from a patient with cystic fibrosis in the absence of carbapenem therapy. Clin Infect Dis. 2008; 46: e137-141. doi: $10.1086 / 588484$

4. Folkesson A, Jelsbak L, Yang L, Johansen HK, Ciofu $\mathrm{O}$, et al. Adaptation of Pseudomonas aeruginosa to the cystic fibrosis airway: an evolutionary perspective. Nat Rev Microbiol. 2012; 10(12): 841-51. doi: 10.1038/nrmicro2907.

5. Livermore DM. Multiple mechanisms of antimicrobial resistance in Pseudomonas aeruginosa: our worst nightmare? Clin Infect Dis. 2002; 34: 634-640.

6. Umadevi S, Joseph NM, Kumari K, Easow JM, Kumar $\mathrm{S}$, Stephen S, et al. Detection of extended beta lactamase, AmpC beta lactamases and metallo beta lactamses in clinical isolates of ceftazidime resistnt Pseudomonas aeruginosa. Brazilian J Microbiol. 2011; 42(4): 12841288. doi: 10.1590/S1517-83822011000400006.

7. Bush K, Jacoby GA, Medeiros AA. A functional classification scheme for $\beta$-lactamases and its correlation with molecular structure. Antimicrob. Agents Chemother. 1995; 39: 1211-1233. PMCID: PMC162717.

8. Zhao WH, Hu ZQ. $\beta$-lactamases identified in clinical isolates of Pseudomonas aeruginosa. Crit Rev Microbiol. 2010; 36(3): 245-58. doi: 10.3109/1040841X.2010.481763.

9. Kiska DL, Gilligan PH. Manual Clinical Microbiology. $8^{\text {th }}$ ed. ASM Press Washington. 2003.

10. Clinical and Laboratory Standards Institute (CLSI). Performance standards for antimicrobial susceptibility testing; twenty-second informational supplement. 2013; Document M100-S23. Wayne, PA.

11. Basak S, Khodke M, Bose S, Mallick SK. Inducible AmpC beta-lactamase producing Pseudomonas aeruginosa isolated in a rural hospital of central India. $\mathbf{J}$ Clin Diagn Res. 2009; 3: 1921-7.

\section{ACKNOWLEDGMENTS}

The authors would like to thank the Research Council of Shahid Beheshti University for their financial support and the Mofid Hospital for providing the bacterial isolates.

\section{CONFLICT OF INTEREST:}

There are no conflicts of interest.

12. Weldhagen GF, Poirel L, Nordmann P. Ambler class A extended spectrum beta-lactamases in Pseudomonas aeruginosa: novel developments and clinical impact. Antimicrob Agents Chemother. 2003; 47(8): 2385-92.

13. Lin SP, Liu MF, Lin CF, Shi ZY. Phenotypic detection and polymerase chain reaction screening of extended-spectrum $\beta$-lactamases produced by Pseudomonas aeruginosa isolates. J Microbiol Immun Infect. 2012; 45(3): 200-7. doi: 10.1016/j.jmii.2011.11.015.

14. Rodríguez-Martínez JM, Poirel L, Nordmann P. Extended-spectrum cephalosporinases in Pseudomonas aeruginosa. Antimicrob Agent Chemother. 2009; 53(5): 1766-71. doi: 10.1128/AAC.01410-08.

15. Jacoby, G.A. \& K. Bush. $\beta$-lactamase classification and amino acid sequences for TEM, SHV and OXA extended-spectrum and inhibitor resistant enzymes. 2012 [updated November 1, 2012]; Available from: http://www.lahey.org/Studies/.

16. Sanders CC, Sanders WE, Goering HV. In vitro antagonism of $\beta$-lactam antibiotics by Cefoxitin. J Antimicrob Chemother. 1982; 21(6): 968-75. PMID: 6981376.

17. Mhlongo N, Govinden U, Egner J, Essack SY. Demographic and microbiological profile of cystic fibrosis in Durban, South Africa. Afr J Microbiol Res. 2014; 8(33): 3118-3122. DOI: 10.5897/AJMR2014.6965.

18. Vali P, Shahcheraghi F, Seyfipour M, Zamani MA, Allahyar MR, Feizabadi MM. Phenotypic and genetic characterization of carbapenemase and ESBL producing Gram-negative bacteria (GNB) isolated from patients with cystic fibrosis $(C F)$ in Tehran hospitals. J Clin Diagn Res. 2014; 8(1): 26-30. doi: 10.7860/JCDR/2014/6877.3916.

19. Aghazadeh M, Hojabri Z, Mahdian R, Nahaei MR, Rahmati M, Hojabri T, et al. Role of efflux pumps: MexAB-OprM and MexXY (OprA), AmpC cephalosporinase and OprD porin in non-metallo- $\beta$ lactmase producing Pseudomonas aeruginosa isolated from cystic fibrosis and burn patients. Infect Genet Evol. 2014; 24: 187-192. doi: 10.1016/j.meegid.2014.03.018.

20. al Naiemi NA, Duim B, Bart A. A CTX-M extendedspectrum beta-lactamase in Pseudomonas aeruginosa and Stenotrophomonas maltophilia. J Med Microbiol. 2006; 55(Pt 11): 1607-8. PMID:17030926.

21. Yakupogullari Y, Poirel L, Bernabeu S, Kizirgil A, Nordmann P. Multidrug-resistant Pseudomonas aeruginosa isolate co-expressing extended-spectrum $\beta$ lactamase PER-1 and metallo- $\beta$-lactamase VIM- 2 from Turkey. J Antimicrob Chemother. 2008; 61 (1): 221-222. doi: 10.1093/jac/dkm420. 